\title{
How self-government in Catalonia has integrated private not for profit care in the public healthcare service
}

\begin{abstract}
This study aims to analyze how the hospital policy of the Catalan government during the period 19802020 was adapted to the specific situation in Catalonia and how it differs from previous policies put in place by the central Spanish government. The methodological approach is to present evidence found through analysis of official documents and study of changes in hospital's affiliations during that particular period. The main contributions are to indicate that the legal status of the hospitals that, in 1980, formed part of the network of hospitals that collaborated with the public system (XHUP in its acronym in Catalan), has changed substantially when compared with the current situation today in 2020. Each case has been studied individually. The changes show a policy that keeps local government involved in healthcare matters and improves the overall efficiency of hospitals.
\end{abstract}

Keywords: hospitals; hospital policies; history of hospital; healthcare in Catalonia

Corresponding author: e-mail: bohigaslluis@ gmail.com

Received 31 August 2020 - Accepted 18 November 2020

This is an Open Access article distributed under the terms of the Creative Commons Attribution-Non-Commercial-No Derivatives License (http://creativecommons.org/licenses/by-nc-nd/4.0/), which permits non-comercial re-use and distribution, provided the original work is properly cited, and is not altered or transformed in any way. 


\section{Introduction}

This paper will analyse the hospital policy of the Catalan government1 (Generalitat de Catalunya) during the period 1980-2020 with special attention to the differences from previous policy put in place by the central Spanish government. The paper further explains how these differences suited the Catalan hospital structure. The following section presents the public hospital situation in 1980, just before the Generalitat assumed its management. Section 3 will be devoted to presenting the main pillars of health policy and Section 4 will analyse changes in the public hospital network. The conclusions will highlight the emphasis of hospital policy and how private social initiatives have been integrated.

\section{Public hospital status in Catalonia 1980: charity and social protection}

Hospitals in Catalonia during the dictatorship have been studied by several authors: Ignasi Aragó (1967) and Jacint Reventós, Anna García and Carme Piqué (1990), and the following is a summary of the state of public hospitals in 1980 in Catalonia, just before the Generalitat assumed responsibility of the health sector.

\subsection{Charity}

The Diputaciones2 ran hospitals in every province of Catalonia providing public healthcare for the poor. Barcelona was the largest province and had the largest hospital, the Clinical and Provincial Hospital, which was managed jointly by the University of Barcelona and the

\footnotetext{
${ }^{1}$ The Catalan Government named Generalitat was reinstated in 1977 after the return of democracy in Spain.

${ }^{2}$ Catalonia is divided in four provinces: Barcelona, Girona, Lleida and Tarragona. Each province has a provincial council that runs provincial services among them is provincial charity.
} 
Diputación de Barcelona (Corbella 2006). The University appointed professors from the Medical Faculty and the Diputación ran the economic management.

In other towns of Catalonia there were hospital charities. They were usually hospitals managed by a foundation built with funds from local benefactors, where the City Council participated and headed the Board. Some municipalities had their own hospitals, for example the Barcelona City Council had two, the Hospital del Mar and the Hospital de l'Esperança, which both had contracts with social security to care for their patients.

The Hospital de la Santa Creu i Sant Pau was a medieval foundation built and maintained by private donations from Barcelona and Catalonia. A great benefactor was Pau Gil, a banker who, upon his death, left half of his fortune to the hospital, which served to build a new building in the early 20th century (Net 2001). The management of the hospital was provided by the City Council of Barcelona and the Bishop of Barcelona, although they were only administrators, without any financial responsibility. The hospital had a social security contract since 1971, and by $1980,80 \%$ of the patients were covered by social security, the rest being private patients or patients whose care was paid for by a charity (Bohigas 2020). As social security had brought more patients to the hospital, the hospital had seen an increase in their income for the provision of services through this system and, due to improvements in the Spanish economy, had seen a decrease in the number of poor people they treated as charity cases and a rise in workers and their family members who were part of the social security system who required care. The hospital therefore gradually changed its main focus, which was originally to provide care for the poor, and became a hospital for workers whose social security paid for the care. 
Some religious orders ran hospitals, the largest being the Hospital de Sant Joan de Déu in Barcelona. The hospital's original focus was caring for poor children and had a contract with the social security system.

\subsection{Social Coverage}

Mutualism was born in the early part of the century to provide care for workers, before social security existed. The most important Mutual Social Security association was the Quinta de Salud La Alianza which was set up to provide medical care to the Barcelona waiters' guild. Over time, it expanded to include many different professional activities and was important to self-employed workers. At one point, it insured over half a million people. In order to provide an adequate amount of care for the large number of people it insured, it had a network of several hospitals, the largest being in Barcelona. Other smaller insurance funds also covered groups of workers and had small hospitals. Some of these hospitals had contracts with social security. The mutual insurance fund system went into crisis, as it was duplicating what was now being provided by the social security system, which became mandatory for all working citizens. Some workers paid both fees for a time, but gradually withdrew from paying the mutual societies when they realised they received the same level of care just through paying for social security.

Social security had built and operated seven major hospitals. The oldest one was the largest: Ciudad Sanitaria Francisco Franco, a hospital of 1,500 beds that opened in 1955. The name "Ciudad Sanitaria" (Healthy City) gives an idea of its size, as it was made up of three buildings, each with a different medical speciality: a General Hospital, a Maternity and Children's Hospital and a Traumatology Unit. There were hospitals run by social security in all four 
provincial capitals. There were three more in other non-capital cities: Tortosa, L'Hospitalet de Llobregat and Badalona.

Social security was compulsory for employed workers and their families. In 1980, social security covered $80 \%$ of the total population of 6 million people in Catalonia. Social security hospitals, despite their large size, were not sufficient to meet the needs of the population. Consequently, social security also employed additional services from other hospitals in the area. In total, there were a hundred hospitals contracted with Social Security where sick people were sent when there were no beds available in the main social security funded hospitals. The two largest hospitals in Catalonia, both in Barcelona, had contracts with the social security system: the Hospital Clinico y Provincial (Asenjo 2017) and Hospital de la Santa Creu i Sant Pau.

\section{Healthcare policy in Catalonia 1980-2020}

In 1979, the central government transferred the responsibility for public health and charity to the Catalan Generalitat, shortly followed by the social security health services in 1981 .

The trend in the early 1980s was the gradual reduction in charity care and the increase of social security. Public welfare was the responsibility of the provincial and local councils and the hospitals of these institutions continued to operate, but they had fewer patients that were taken in as charity cases and more social security members. Private charities and religious orders saw a reduction in both the number of patients and the income from benefactors. Private insurance funds lost their beneficiaries because social security had become mandatory in Catalonia and therefore their hospitals had fewer clients of their own and more social security patients.

The social security system built three new hospitals in Catalonia to increase its capacity, located in the cities of Badalona, Terrassa, and Vic. When they were later transferred to the Generalitat 
that gave them around 2,000 more beds, but this was not enough to cater for the increased demand.

\subsection{The Creation of the Hospital Network for Public Use}

The basis of the hospital policy of the Generalitat in the 1980s was the creation of the Public Use Hospital Network (XHUP). This network included all hospitals that would care for patients financed by public funds. The concept for this network was set in the health plan (Generalitat de Catalunya 1983) and it was put into legislation by a Decree issued two years later3.

The social security system treated its patients in its own hospitals, but as the number of patients covered by social security increased they hired other public and private hospitals to treat this "overflow" of patients and paid these hospitals a certain amount per stay, with these hospitals being considered as "complementary" to the social security system, but not necessarily a part of it. The social security system continued to build hospitals to meet the growing demand of workers and when it opened a new hospital, it stopped the contract it had with the complementary hospitals. The XHUP changed this dynamic as it considered all the hospitals involved in the network as equal and providing a public service. Therefore, under this new system new hospitals were only built in areas that didn't have any existing hospitals. XHUP hospitals, regardless of their ownership, provided stable service to all patients covered by social security (Bohigas 2014).

A basic condition for a hospital to be within the XHUP was to be accredited, that is to pass an external assessment of the care standards in the hospital, to guarantee the user a certain level of

\footnotetext{
3 “Decret 202/1985, de 15 de juliol, de creació de la Xarxa Hospitalària d’Utilització Púbica.” Diari Oficial de la Generalitat de Catalunya, July 29, 1985.
} 
care quality. Previously to the XHUP being set up, the social security did not require an assessment such as this to guarantee a certain standard of care across the board, and among the 100 hospital contracts they had, there were rather differing levels of quality of care. By the time the XHUP came about and ran the assessments, only half of the hospitals previously associated with the social security system passed the accreditation and became integrated into the XHUP. The others lost the contract and changed towards purely private care or began offering social healthcare services.

Social security negotiated and paid for each hospital's contract individually, which meant that two hospitals, although equal in many aspects, could have completely different contracts. Later they attempted to correct this mess with a payment regulation that ranked the hospitals in more than twenty categories according to the structural characteristics of each hospital. According to the residual philosophy of the contracts, only stays were paid, as the original purpose of the contract was to cover the lack of beds in the main social security hospitals.

The Generalitat later reduced these twenty or so hospital categories to three and for each category allocated a set price, called a Basic Assistance Unit (UBA). The UBA corresponded to an overnight stay and had a different price for each of the three types of hospital. The Generalitat paid for external consultations and emergencies, it was thus recognized that the contracted hospitals were contributing all kinds of care and not only with overnight stays. 


\subsection{The creation of the Catalan Institute of Health}

In 1983, the Catalan Institute of Health (ICS)4 was created to manage the seven social security hospitals, as well as the contracts with other hospitals. When the Catalan Health Service was created, the management of the contracts was transferred to this organisation. The ICS was transformed into a public company by law in 20075. Consequently, their next move was to attempt to turn each hospital into a management unit with its own legal personality for more efficient and effective management, but this was not successful, as neither the corporate structure of the ICS nor the unions wanted to lose power.

3.3. The Llei d'Ordenació sanitària de Catalunya and the creation of the Catalan Health Service

The Ley General de Sanidad6 made it mandatory for every autonomous community in Spain to have its own regional health services. All the regions created their own Regional Service to manage the centres and services transferred, which was equivalent to the already established Catalan Institute of Health. In Catalonia, there were hospitals built by religious, municipal, mutual and foundation entities, independent of the social security services, but that were needed to provide assistance to citizens due to the historical lack of public investment in Catalonia. In 1990, the Parliament of Catalonia approved the Llei d'Ordenació Sanitària de Catalunya (LOSC)7, which created the Catalan Health Service (Catsalut). The Catalan Health Service would encompass both social security services and private contracted hospitals. This

\footnotetext{
4 “Llei 12/1983 de 14 de juliol, d'administració institucional de la sanitat, l'assistència i els serveis socials de Catalunya." Diari Oficial de la Generalitat de Catalunya, July 15, 1983.

5 "Llei 8/2007 de 30 de juliol, de l'Institut Català de la Salut." Diari Oficial de la Generalitat de Catalunya, August 3, 2007.

6 "Ley 14/1986, de 25 de abril, General de Sanidad." Boletin Oficial del Estado, April 29, 1986.

7 “Llei 15/1990, de 9 de juliol, d'ordenació sanitària de Catalunya." Diari Oficial de la Generalitat de Catalunya, July 30, 1990.
} 
philosophy was present in the speech made by the Health Minister Xavier Trias to the Parliament of Catalonia in 1990 when he presented the proposal of the Law: "To take advantage of the existing, varied, rich, and long-standing infrastructure, the fruit of the collective effort of Catalan society." (Trias 1990)

The Act confirmed the Hospital Network of Public Utility as the model for organising the hospital network. The funding provided by the Catalan Generalitat that was to be used for the XHUP hospitals was managed by the Catalan Health Service (Servei Català de la Salut). The hospitals that belonged exclusively to the social security system were a separate case (managed by the Catalan Institute of Health) since these centres had a budget assigned by the Parliament of Catalonia.

\section{Hospital policy 1985-2020 from XHUP to SISCAT}

The Public Utility Hospital Network (XHUP) created in 1985 was consolidated by the Llei d'Ordenació sanitària de Catalunya, but only covered acute hospitalisation (Departament de Sanitat 1994). The XHUP model was extended to two other types of hospital, psychiatric hospitals, and social healthcare centres, and in 1999, two networks were created: a) centres, services and mental health institutions8, and b) centres of services and social healthcare establishments9 The strategy was to apply the XHUP formula, namely a consolidated network of hospitals with minimum care standards and information systems, to care for psychiatric patients and patients who required social healthcare services.

\footnotetext{
8 "Decret 213/1999, de 27 de juliol, pel qual es crea la xarxa de centres, serveis i establiments de salut mental d'utilització pública de Catalunya." Diari Oficial de la Generalitat de Catalunya, August 3, 1999.

9 "Decret 242/1999, de 31 d'agost, que crea la xarxa de centres, serveis i Establiments sociosanitaris d'utilització pública de Catalunya.”, Diari Oficial de la Generalitat de Catalunya, August 31, 1999.
} 
In 2000, the three networks were consolidated (acute, psychiatric and social healthcare patients) in a single list called the Integrated Health System (SISCAT).10 In addition to hospital facilities, it also included primary care centres.

Ten years later, in 2010, SISCAT was reformed and expanded, bringing all the hospitals together in a single network.11 Two other networks were added: "Community-level health centres and services", which included primary care centres, and "Health transportation services". SISCAT included hospitals from the social security system, from the Generalitat, public hospitals and the "Privately owned centres whose services are needed to implement the provisions of the Health Plan of Catalonia."

As of August 2020 , the Department of Health website provides information on the composition of SISCAT: 68 hospitals, 434 primary care facilities, 102 social healthcare centres, 40 mental health centres, 428 basic and advanced life support ambulances (SVB and SVA) and 4 air ambulances, as well as over 900 emergency transportation ambulances.

The following table analyses the composition of SISCAT's acute hospital network as of 2020 and compares it to the Hospital Network in 1985. This analysis seeks to examine the evolution in the last 35 years of the hospital services that are funded by the Generalitat.

\footnotetext{
10 "Decret 378/2000, de 21 de noviembre, pel qual es configura el sistema sanitari integral d'utilització pública de Catalunya (SISCAT).”, Diari Oficial de la Generalitat de Catalunya, December 14, 2000.

11 "Decret 196/2010, de 14 de desembre, del sistema sanitari integral d'utilització pública." Diari Oficial de la Generalitat de Catalunya, December 16, 2010.
} 
TABLE 1. SISCAT’s Hospital Network 1985 and 2020

\begin{tabular}{|l|c|c|}
\hline Type of hospital & XHUP 1985 * & SISCAT 2020 *** \\
\hline Related to local councils & 26 & 16 \\
\hline Mutual funds & 8 & 1 \\
\hline Diputaciones & 4 & 0 \\
\hline Red cross & 3 & 0 \\
\hline Others & 4 & 2 \\
\hline ICS & 7 & 8 \\
\hline Public companies & & 6 \\
\hline Consortia (Generalitat-Local council) & 3 & 16 \\
\hline Church & 2 & 2 \\
\hline Sant Joan de Déu & 3 & 3 \\
\hline Privately owned & 4 & 2 \\
\hline Foundation & 64 & 7 \\
\hline Total & & 63 \\
\hline
\end{tabular}

Sources: (*) "Decret 202/1985, de 15 de juliol, de creació de la Xarxa Hospitalària d'Utilització Púbica." Diari Oficial de la Generalitat de Catalunya, July 29, 1985;

(**)Departament de Salut. 2020.

The number of hospitals stays fairly consistent between the two dates, but their composition has changed greatly. Only half of the hospitals that were open in 1985 are still in operation in 2020. Others have changed legal status, building or location.

4.1. The creation of consortia between the Generalitat and local councils

In 1985 at the XHUP there was no Consortium, while in 2020 at SISCAT there are 16 hospitals managed by 12 Consortia shared between the Generalitat and local City Councils.

The growth of the Consortium legal formula has run in parallel to the decline in hospitals linked to City Councils, that reduced in number from 26 in 1985 to just 16 in 2020 . The link between hospitals and local councils was generally through the legal formula of a Foundation, on whose Board the City had representatives, including the mayor usually as president. Only a few hospitals in 1985 were truly municipal dependencies, among which were the hospitals of Barcelona City Council or Sant Joan de Reus (Anguera 1990). 
When management of social security hospitals was taken over by the Generalitat, two hospitals were still under construction, in the cities of Vic and Terrassa. In those cities there were hospitals managed by foundations that were linked to the respective municipalities. When the social security system transferred the hospitals of Vic and Terrassa to the Generalitat, they were empty buildings without staff or equipment. The traditional social security system would have hired staff and equipped these hospitals and when it started them it would have discontinued the contracts with the municipal hospitals. As a result, these hospitals would have closed and their staff would have been unemployed. Consortiums between the Generalitat and the local councils allowed the transfer of staff from the old hospital to the new one and also part of the equipment. In this way the new hospitals were set up more quickly and without the legal constraints of social security. The old hospitals were reconverted into social healthcare centres. In both cases, the Generalitat retained the majority of the governing body seats of the Consortia.

The consortium formula was flexible, allowing for a number of options: a) to retain existing hospitals and their staff, b) to hire staff not bound to social security legislation, c) to keep local councils linked to public health services, d) to maintain the local tradition of the hospital, and e) to initiate social healthcare programs.

In the city of Sabadell at the beginning of the eighties, a variety of hospitals existed that belonged to various different institutions: the University, the City Council, private mutual insurance funds, etc. These hospitals were small in size with few services and were competing with each other, without being able to offer better services. To improve hospital services, all hospitals were integrated into a single legal entity to facilitate the integration of services, while avoiding duplication and encouraging specialisation. The new Hospital of the Autonomous University was chosen to centralise all the services of the hospitals of the city. A Consortium 
with a majority from the Generalitat was created, with participation from the City Council of Sabadell and all the institutions that had originally owned the hospitals in the area.

The Consortium formula has been successfully applied to 16 hospitals. The biggest operation was in the city of Barcelona in 2010, when the Generalitat and the City Council created a Consortium called the Parc de Salut Mar with the Generalitat having the majority of seats on the Board.

The Hospital Clinic, which was also the teaching hospital for the University of Barcelona, was transferred to the Generalitat by the Provincial Council of Barcelona. To manage the hospital, a Consortium was created between the Generalitat and the University of Barcelona.

One specific case is a consortium that was formed by two city councils without the participation of the Generalitat, to jointly manage the hospitals of Sant Antoni Abad and Sant Camil.

\subsection{The creation of Public Companies}

Public companies have been created by the Generalitat to manage hospitals when there was no need to share governance with a local council.

Provincial Councils had hospitals and services to meet their responsibilities for charity and mental health. The Councils of Girona, Lleida and Tarragona transferred their hospitals to the Generalitat, which then chose to create public companies to manage these services.

The Spanish Association Against Cancer (Asociación Española Contra el Cáncer, AECC) had built a hospital in L'Hospitalet de Llobregat near Barcelona with the intention of creating a specialised oncology hospital. The association was unable to launch the hospital and gave it to 
the Generalitat, which created a public enterprise to manage it under the title of the Catalan Institute of Oncology dedicated to cancer care.

\subsection{Mutual funds}

Most hospitals that belonged to mutual insurance funds have disappeared, from eight in 1985 and now only one. Mutual funds provided health care to their members which was similar to that of social security. After social security contribution was made mandatory, paying in addition for separate mutual insurance became an extra cost. Membership was declining and the funds became unworkable. One of the most significant cases was that of the Quinta de Salut La Alianza. At its peak, it was the most important mutual insurance society in Catalonia, having been founded at the beginning of the 20th century and had a number of hospitals, four of which were integrated into the XHUP. The crisis of the mutual insurance fund model that was mentioned earlier affected this entity profoundly. Eventually it sold its best and largest hospital, the Hospital Sagrat Cor, to a private company and disappeared as a mutual insurance company. The only surviving mutual insurance fund company has been the Mutua de Terrassa, which has diversified and survived.

\subsection{Church}

In 1985 there were five hospitals that belonged to religious orders. In 2020, there are still five but with some notable changes, especially in relation to those managed by the Order of Sant Joan de Déu. In 1985 the Order operated two children's hospitals, one in Barcelona and the other in Manresa.

In the eighties, there were five hospitals in Manresa: one was a Foundation chaired by the mayor, another belonged to the Caixa de Manresa, a third to a Mutua (a private mutual fund), 
a fourth to a religious order of nuns, and a fifth to the Hospital Order of Sant Joan de Déu. The plan was to integrate all hospitals into a single unit to improve performance. The main unit chosen was the Hospital Sant Joan de Déu that was expanded in capacity and incorporated all the other hospitals into it. The legal solution adopted was a Foundation where the Order of Sant Joan de Déu, the City Council of Manresa and the Mutua Manresana are all represented.

The Sant Joan de Déu Order built a new hospital in Sant Boi de Llobregat which is also integrated into SISCAT.

\subsection{Foundations}

Most foundations were associated with town councils, but some did not have this municipal link and have continued as private foundations. A special case is the Hospital de la Santa Creu i Sant Pau, where the Generalitat invested in the new hospital and was therefore included in the new Board set up in conjunction with the City Council and the Bishop of Barcelona.

\section{Conclusions}

The main objectives of the Generalitat's hospital policy between 1980 and 2020 have been: a) maintaining the participation of city councils in hospital governance; and b) improving hospital efficiency.

a) Retaining City Council participation in hospital governance

In 1980, half of the hospitals providing public health care were linked to the City Council of the town where they were based. Some municipalities had invested in the construction of hospitals and their maintenance, as was the case with Barcelona City Council, but most hospitals were private foundations. These foundations were created by local benefactors who 
had donated money and property to hospitals. Generally, the founders included the city hall and its mayor as members of the Board of the Foundation in order to ensure its continuity and to ensure that attention was paid to the poorest section of the local population (Reventós 1996).

By 2020, half of the hospitals linked to local foundations were still in operation, while the other half had been transformed into Consortia with the Generalitat in majority control and local councils, and in some cases the original foundations, holding minority stakes. If the hospital was very old and needed a major redevelopment, the Generalitat invested in the construction of a new hospital and created a Consortium where it had a legal majority, and kept the link to the City Council and the original foundation. In many cases, the former hospital was converted into a social healthcare centre. This municipal involvement in hospitals that provide public service, be it in the form of a foundation or of a Consortium, is unique within Spain. In other regions local councils have no role in hospital care.

b) To improve hospital efficiency

Hospital efficiency when hospitals were managed by Social Security was very poor. The hospital staff working under the social security system enjoyed a special status that was equivalent to that of civil servants and management was centralised at the headquarters in Madrid. The transfer of social security services to each autonomous community made it possible to reduce the centralisation of management and bring decisions closer to the source of problems. This did not change the legal structure of the institution, in which hospitals had no autonomy and bureaucracy was a problem. The hospitals did not have legal autonomy but were treated as sections of a centralised body. Studies on the efficiency of hospitals in Spain 
corroborate the fact that hospitals with legal autonomy had better efficiency indicators than those managed by the classic social security model (Pérez Romero et al. 2018).

In the case of Catalonia, consortia and public companies were the legal formulas chosen by the Generalitat in order to preserve autonomy in the governance of the hospitals.

In the last decade, some restrictions have appeared related to the management autonomy of hospitals in Catalonia. A 2010 publication by the Generalitat (Pozo and Planas 2010) explained the reasons for limiting the autonomy of management. An important milestone was the integration of consortia and public companies into the European Accounting System (SEC 2010), which classifies a public institution as one that, although holding a private legal status, receives most of its income from the government, and this involves applying public procurement legislation. Another limitation was the budget reductions for 2010 and beyond, and the financial control imposed by the Treasury Department to reduce the public deficit. As a result of these measures, the bureaucratic gap between these management formulas and the classic social security policy has narrowed, but it seems that it is still room enough to enable more efficient management, especially as the staff is not subject to the Staff Regulations of the social security and that there is no prior control of expenditure.

\section{References}

Anguera, Pere. 1990. Hospital Sant Joan de Reus 1240-1990. Reus: Hospital Sant Joan de Reus. Aragó, Ignasi. 1967. Els Hospitals a Catalunya, Barcelona: Altés.

Asenjo, Miguel Angel. 2017. Una reforma hospitalaria radical y consensuada, Barcelona: Universitat de Barcelona.

Bohigas, Lluis. 2014. "El model sanitari català abans de la LOSC." Referent. Papers de la Fundació Unió, 14:6-12. 
Bohigas, Lluís. 2020. "La modernització de l’Hospital de la Santa Creu i Sant Pau (1965-1980)." Gimbernat 73: 153-167. doi: 10.1344/gimbernat2020.73.9.

Corbella, Jacint. 2006. Historia de l'Hospital Clínic de Barcelona, Barcelona: Universitat de Barcelona.

Departament de Salut. 2020. Accessed August 25. https://catsalut.gencat.cat/ca/coneixcatsalut/presentacio/model-sanitari-catala/siscat.

Departament de Sanitat i Seguretat Social. 1994. La Xarxa Hospitalària d'Utilització Pública de Catalunya. Història d'una diversitat. Barcelona: Generalitat de Catalunya.

Generalitat de Catalunya. 1983. Planificació sanitària pública a Catalunya. Desplegament del Mapa Sanitari de Catalunya. Barcelona: Departament de Sanitat i Seguretat Social.

Net, Àlvar. 2001. "Hospital de la Santa Creu i Sant Pau, reflexions en el seu 600 aniversari." In L'Hospital de la Santa Creu i Sant Pau 1401-2001, various authors, 234-46 Barcelona: Lunwerg editores.

Pérez Romero, Carmen, M. Isabel Ortega Diaz, Ricardo Ocaña Riola, José Jesús Martin Martin. 2018. "Análisis multinivel de la eficiéncia técnica de los hospitales del Sistema Nacional de Salud español por tipo de propiedad y gestión." Gaceta Sanitaria 33(4): 325-332. doi: 10.1016/j.gaceta.2018.02.005.

Pozo, Ana, and Ivan Planas. 2010. "Les empreses públiques i els consorcis en el marc del model sanitari català." In Evolució del model de governança i gestió de les entitats participades pel Servei Català de la Salut, directed by Ivan Planas, 57-79. Barcelona: Generalitat de Catalunya, Departament

Salut.

https://catsalut.gencat.cat/web/.content/minisite/catsalut/coneix_catsalut/organitzacio/empresespubliques-consorcis/model-de-gestio-catala.pdf.

Raventós, Jacint, Anna García, and Carme Piqué. 1990. Historia de la Medicina Catalana sota el franquisme. Barcelona: Editorial Hacer.

Reventós, Jacint. 1996. Els hospitals i la societat catalana. Barcelona: Editorial Hacer.

Trias, Xavier. 1990. "Discurs de presentació del projecte de llei d'ordenació sanitària de Catalunya al Parlament de Catalunya." Diari del Parlament de Catalunya. June 13. de juny de 1990.

This is an Open Access article distributed under the terms of the Creative Commons Attribution-Non-Commercial-No Derivatives License (http://creativecommons.org/licenses/by-nc-nd/4.0/), which permits non-comercial re-use and distribution, provided the original work is properly cited, and is not altered or transformed in any way. 